\title{
EFFECT OF MATRIX METALLOPROTEINASE INHIBITOR FROM MULBERRY FRUIT EXTRACT ON THE MICROTENSILE BOND STRENGTH STABILITY: AN IN VITRO STUDY
}

\author{
Rania Mosallam*, Nermin Younis ${ }^{* *}$, Hadeel Farouk ${ }^{* * *}$ and Osama Mosallam****
}

\begin{abstract}
Objectives: The present in vitro study aimed to analyze the effect of two Mulberry fruit extracts on microtensile bond strength of an etch \& rinse adhesive immediately and after thermocycling.

Materials and Methods: Flat dentin surfaces of 30 sound human molars were bonded with an etch and rinse adhesive. Dentin surfaces were left untreated (control group) or were pretreated with either Morus alba water extract, Morus alba alcohol extract, Morus nigra water extract or Morus nigra alcohol extract. Nano-hybrid resin composite were incrementally built-up. The tooth/ composite specimen was serially sectioned in order to produce beams of $0.9 \pm 0.1 \mathrm{~mm}$ in thickness. Each group was subdivided into two subgroups whether the teeth/composite specimens subjected to thermocycling or not. Each beam was individually fractured by a micro tensile testing machine. The data recorded in MPa, were tabulated and statistically analyzed.
\end{abstract}

Results : Specimens treated with Morus alba and Morus nigra water extracts yielded significantly higher mean bond strengths than alcohol extracts in immediate micro-tensile bond values and after thermocycling. In addition ,Morus alba water extract revealed no statistically significant difference immediately and after thermocycling.

Conclusion : Dentin pretreatment with Mulbery water extracts has no adverse effect on the immediate microtensile bond strength and it was able to maintain bond stability of adhesive to dentin.

KEY WORDS: Mulberry, Microtensile bond strength, Matrix metalloproteinases

\footnotetext{
* Conservative Dentistry Department, Faculty of Dentistry, Cairo University, Egypt. ** Pharmacognosy Department, Faculty of Pharmacy, Ahram Canadian University, Egypt *** Operative Dentistry Department, Faculty of Oral and Dental Medicine, Ahram Canadian University, Egypt **** Restorative and Dental Material Research Department, National Research Centre, Egypt.
} 


\section{INTRODUCTION}

The main objective of adhesive dentistry is to improve the bond durability between tooth structure and the restorative material. Matrix metalloproteinases (MMPs) and cysteine cathepsins contribute to the enzymatic degradation of the collagen matrix ${ }^{[1,2]}$. MMPs are present in dentin matrices as inactive proenzymes, but promote the degradation of collagen fibril and extracellular matrix when activated ${ }^{[3]}$. The low-pH environment caused by acid etching or acidic monomers can modulate the activity of MMPs and the interaction with cysteine cathepsins ${ }^{[4,5]}$. The degradation occurs in consequent stages: first water is absorbed by the polymer then resin components are leached from the hybrid layer; and finally, the exposed collagen fibrils are degraded by (MMPs) and/or by cysteine cathepsins ${ }^{[6-8]}$. MMP-8 is capable of converting type I into fragments of 3/4- and 1/4-length ${ }^{[9]}$.

The understanding of the mechanism collagen degradation has encouraged the evaluation of substances that may inhibit the function of both MMPs and cysteine cathepsins. Different strategies have aimed to preserve the collagen fibrils using different matrix metalloproteinase inhibitors as a pretreatment or by admixing it to primers ${ }^{[10-14]}$. The application of chlorhexidine digluconate (CHX) has been found to be valuable in the preservation of the bond strength over time ${ }^{[15,16]}$. Recent researches have highlighted the toxic effect of $\mathrm{CHX}$ on both odontoblast-like cells ${ }^{[17]}$, and stem cells ${ }^{[18]}$. Therefore, it is relevant to find an alternative MMP inhibitor to enhance bonding durability. Various compounds from natural sources have shown promising inhibition of matrix metalloproteinases especially some alkaloids, flavonoids and phenolic compounds from plant sources.

The anthocyanin group of polyphenols demonstrated beneficial pharmacological activities as anti-inflammatory, antioxidant and chemoprotective properties ${ }^{[19]}$. It was found to reduce the expression of MMP and stimulating the expression of matrix metalloproteinase-2 inhibitor (TIMP-2) ${ }^{[20]}$. Anthocyanins responsible for red, purple, and blue colors of vegetables and some tropical fruits such as berries, grapes which have high anthocyanins content ${ }^{[21]}$.

Mulberry fruits are valuable horticultural sources of health benefits compounds. They belong to the genus Morus, family Moraceae which is composed of 10-16 species of deciduous trees and cultivated in many temperate world regions ${ }^{[22]}$. Morus nigra known as black mulberry and Morus alba known as white mulberry fruitsare rich in many bioactive components such as alkaloids, flavonoids and carotenoids, fats, vitamins, and minerals ${ }^{[23]}$.

Mulberry exhibit many biological activities such as prevention and treatment of human cancer, cardiovascular disease and modulates several apoptotic pathways and matrix metalloproteinases (MMPs) ${ }^{[24,25]}$. In addition, Morus alba root bark extract exhibits antibacterial activity against oral pathogens (Streptococcus mutans) causing dental caries $^{[26]}$. While Morus alba L. fruit exhibits hypolipidemic and antioxidant effects ${ }^{[27-29]}$. The bioactivity of mulberry fruits was linked to the presence of phenolic compounds such as anthocyanins. Anthocyanins compounds isolated from Morus nigra and Morus alba fruits are cyanidin 3-O-rutinoside and cyanidin 3-O-glucoside which reduced extracellular matrix proteinases including matrixmetalloproteinase-2 (MMP-2) $)^{[30,31]}$. Moreover, it contains flavonoid compounds such as kaempferol, rutin, scopolitin and quercetin in addition to other essential organic acids and vitamins such as vitamin $\mathrm{C}^{\text {[23] }}$.

However, to date, the efficacy of fruit extracts MMP inhibitors in dentistry has not been completely investigated. Thus, the aim of the present study was to determine the microtensile bond strength (TBS) of an etch and rinse adhesive after pretreatment with different Mulberry fruit extracts immediately and after thermocycling. This study tested the null 
hypothesis that: A) micro TBS is not affected by pretreatment extracts and $B$ ) aging of resin-dentin bonds is not adversely affected by thermocycling.

\section{MATERIAL AND METHODS}

\section{Preparation of total alcohol and water fruits extracts}

Two grams of air-dried powdered fruits of both Morus nigra and Morus alba were extracted using methanol $(50 \mathrm{ml} \times 2)$ at room temperature. The combined extracts were evaporated in rotary evaporator (Buchi, G. Switzerland) to dryness under reduced pressure to yield $0.47 \mathrm{gm}$ and 0.53 gm respectively. The exctracted powder samples were dissolved in $100 \mathrm{ml}$ distill water by stirring for $1 \mathrm{hr}$ using Magnetic stirrer (R. Espinar, S.L.) then filtered using Whatman (No.1) filter paper.

For water extracts, each of $2 \mathrm{gm}$ air-dried powdered fruits of both Morus nigra and Morus alba were topped with $100 \mathrm{ml}$ boiled distilled water and incubated for 2 hours at room temperature then filtered using Whatman (No.1) filter paper.

\section{Sample preparation}

Thirty non-carious human molars were collected for this study.All collected teeth were extracted for therapeutic reasons from patients of age group (35-45 years). Selected teeth were free of caries and showed no hypoplastic defects or cracks. The selected teeth were thoroughly cleaned from calculus, tissue deposits, polished with pumice and rotating brush at conventional speed. The teeth were stored in saline solution at room temperature and were used within four weeks after extraction.

A specially fabricated cylindrical, split Teflon mould of $19 \mathrm{~mm}$ height, $22 \mathrm{~mm}$ external diameter and $17 \mathrm{~mm}$ internal diameter was used for the fabrication of acrylic resin blocks. Each tooth was vertically embedded into self-curing acrylic resin (Acrostone Dental Factor, England) up to the level of the cervical line with their occlusal surface being parallel to the acrylic resin base.

\section{Grouping}

The teeth were allocated randomly to five groups of 6 teeth each, according to the dentin surface pretreatments, namely Group 1: water extract of Morus alba fruit; Group 2: alcohol extract of Morus alba fruit; Group 3: water extract of Morus nigra fruit; Group 4: alcohol extract of Morus nigra fruit and Group 5: no pretreatment (control). Each group was further subdivided into two subgroups according to time of bond strength testing whether immediately after storage in water for 24 hours or after thermocycling.

\section{Teeth preparation}

Occlusal enamel of teeth was removed perpendicular to tooth long axis and parallel to acrylic resin base to obtain flat mid coronal dentin surface at a standardized depth at approximately $4 \mathrm{~mm}$ above cementoenamel junction using a slow speed diamond saw (Isomet, Buehler Ltd., Lake Bluff, IL, USA). Exposed dentin surface was ground with rotary grinding milling machine using \#180-grit silicon carbide paper (Gamberini s.r.1, Via Della Bastia, Caslecchio Di Reno, Italy) under continuous water coolant to create a uniform thickness of smear layer.

\section{Bonding procedure}

Etch and rinse adhesive system was applied to dentin surfaces following the manufacturer's instructions. Etching of exposed dentine was performed for 15 seconds using Scotch bond ${ }^{\mathrm{TM}}$ universal Etchant (3M ESPE, USA). Fruit extracts were then applied on etched dentin for 60 seconds with microbrush under a slight rubbing motion. The excess was removed using an absorbing paper, leaving dentin with a glistening, moist aspect. The adhesive system was then applied with a microbrush in two consecutive coats followed by air blow 
for five seconds and light cured for 10 seconds with LED light curing unit Light (Elipar LED Curing Light; 3M ESPE) at an output intensity of $700 \mathrm{~mW} / \mathrm{cm}^{2}$.

\section{Resin Composite restorative material application}

A specially constructed two halves spilt Teflon mold with a central square hole $(5 \mathrm{~mm} X 5 \mathrm{~mm}$ in diameter and $4 \mathrm{~mm}$ in depth) was constructed for composite build up. Nano filled resin composite (Z 350, 3M ESPE, USA) was built up into two increments each $2 \mathrm{~mm}$ in thickness. Each increment was inserted using Teflon tipped instrument and photoactivated for 20 seconds with the same LED light curing unit and output intensity. The specimen was stored in distilled water at $37^{\circ} \mathrm{C}$ for $24 \mathrm{~h}$ to ensure sufficient polymerization.

\section{Beam preparation}

After 24 hours storage in water at $37^{\circ} \mathrm{C}$, mounting the tooth/composite block in the gripping attachment was done. The tooth/composite specimen was sectioned into sticks, using a $0.3-\mathrm{mm}$ thick diamond coated disc (Buehler, IL, USA), at $2050 \mathrm{rpm} ; 8.8 \mathrm{~mm} / \mathrm{min}$ feeding rate under copious coolant, mounted in an automated diamond saw (Isomet 4000, BuehlerLtd., Lake Bluff, IL, USA). Sectioning was done first in a bucco-lingual direction then mesio-distally by rotation $90^{\circ}$ clockwise. Resultant beam was $0.9 \pm 0.1 \mathrm{~mm}$ in thickness and $3.5 \pm 1 \mathrm{~mm}$ in length. The four central sticks from each specimen were selected and their thickness was checked using a caliper. Beams were stored in distilled water at room temperature in a tight-seal plastic cone.

\section{Micro-tensile bond strength measurement}

Each beam was held on the universal testing machine (Instron, MA, USA) through cementation in the groove of the Geraldeli's jig by its ends using cyanoacrylate-based glue (Zapit, DVA Inc, USA). Applying the tensile load, at a cross-head speed of $0.5 \mathrm{~mm} / \mathrm{min}$, was done till the bonded beams failed. The strength of microtensile bond was calculated in
Mega Pascal (MPa) (Bluehill Lite software, Instron, MA, USA).

\section{Thermo-cycling}

The specimens were subjected to 1000 thermal cycles in three water baths for 20 seconds with temperature of $5^{\circ} \mathrm{C}$ followed by $55^{\circ} \mathrm{C}$ for 20 seconds each, with an intermediary bath $37^{\circ} \mathrm{C}$.

\section{Statistical analysis}

Statistical analysis was performed with IBM ${ }^{\circledR}$ SPSS $®$ Statistics Version 20 for Windows .The bond strength values were statistically analyzed for normality using Kolmogorov-Smirnov and Shapiro-Wilk tests and showed parametric (normal) distribution. For comparison between more than two groups in non-related samples One way ANOVA followed by Tukey post hoc test was used. In nonrelated samples independent sample t-test was used. The significance level was set at $\mathrm{P} \leq 0.05$.

\section{RESULTS}

The mean micro TBS for each group was computed (Table1, Figure 1). There was a statistically significant difference between immediate micro TBS of different groups. The highest mean value was found in water extracts of both Morus nigra and Morus alba followed by control group while the least mean value was found in alcohol extracts. The micro TBS of the etch and rinse adhesive decreased after thermocycling with non-statistically significance difference. The highest mean value was found in water extracts of both Morus alba and Morusnigra. In addition, a statistically significant decrease was found between immediate bond strength values and after thermo cycling in all groups except in Morus alba extracts in which the initial high bond strength microTBS value declined only slightly but not significantly after thermocycling. The results of Two way ANOVA showed that different tested groups and thermocycling had a statistically significant effect .However, the interaction between the two variables had no statistically significant effect (Table 2). 
TABLE (1): The mean, standard deviation (SD) values of tensile bond strength of different groups.

\begin{tabular}{|c|c|c|c|c|c|}
\hline \multirow[t]{3}{*}{ Variables } & \multicolumn{4}{|c|}{ Tensile bond strength } & \\
\hline & \multicolumn{2}{|c|}{$\begin{array}{c}\text { Before } \\
\text { thermocycling }\end{array}$} & \multicolumn{2}{|c|}{$\begin{array}{c}\text { After } \\
\text { thermocycling }\end{array}$} & \multirow{2}{*}{$p$-value } \\
\hline & Mean & SD & Mean & SD & \\
\hline Control & $28.38^{\mathrm{abA}}$ & 6.68 & $17.39^{\mathrm{aB}}$ & 1.71 & $0.007 *$ \\
\hline MA/W & $29.30^{\mathrm{abA}}$ & 7.31 & $20.55^{\mathrm{aA}}$ & 8.85 & $0.127 n s$ \\
\hline MA /A & $17.39^{\mathrm{bA}}$ & 1.63 & $10.26^{\mathrm{aA}}$ & 8.28 & $0.096 n s$ \\
\hline $\mathbf{M N} / \mathbf{W}$ & $35.03^{\mathrm{aA}}$ & 5.24 & $20.60^{\mathrm{aB}}$ & 5.97 & $0.004 *$ \\
\hline MN /A & $19.72^{\mathrm{bA}}$ & 8.82 & $18.05^{\mathrm{aA}}$ & 7.84 & $0.760 \mathrm{~ns}$ \\
\hline$p$-value & \multicolumn{2}{|c|}{$0.002 *$} & \multicolumn{2}{|c|}{$0.166 \mathrm{~ns}$} & \\
\hline
\end{tabular}

Means with different small letters in the same column indicate statistically significant difference, means with different capital letters in the same row indicate statistically significant difference. *; significant $(p<0.05)$ ns; non-significant ( $p>0.05)$

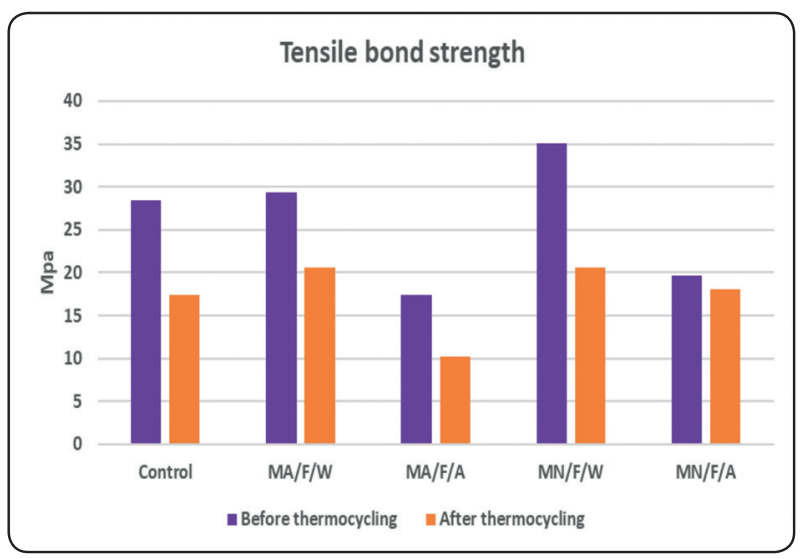

Fig. (1) Bar chart representing tensile bond strength

\section{DISCUSSION}

The understanding that dentin matrix metalloproteinases and cysteine cathepsins are both involved in the hybrid layer degradation process has driven the search for natural products that deactivate these enzymes. Thus, this study aimed at assessing the effect of pretreatment with Mulberry fruit water and alcohol extracts on both immediate bond strength and after thermocycling. The null hypothesis that the micro TBS is not affected by pretreatment with fruit extracts was corroborated with alcohol extracts. However, pretreatment with all water extracts prevented micro TBS loss of etch and rinse adhesive significantly.

The set up of the present study was done using mid coronal flat dentin surfaces as the bond was shown to be directly affected by dentin location and the cavity configuration ${ }^{[2,33]}$. Also ,mid coronal flat dentin surfaces allowed for the use of multiple beams per tooth. Etch and rinse adhesive system was selected due to the significant levels of MMP-2 and MMP-9 activity in comparison with self-etching adhesives $^{[34]}$. The tested solutions were applied in a separate step with 60 seconds application time, which seems realizable under clinical conditions. In addition, the addition of MMP inhibitors into adhesives might affect the degree of conversion and E-modulus of products ${ }^{[35]}$. Long term water storage and thermocycling are the most commonly used artificial ageing technique. The bond durability might become more apparent with thermocycling ${ }^{[13]}$. The ISO TR 11450 standard indicates that 500 cycles with alternate temperatures of $5^{\circ} \mathrm{C}$ and $55^{\circ} \mathrm{C}$

TABLE (2) Results of Two-way ANOVA for the effect of different variables on Tensile bond strength.

\begin{tabular}{|l|c|c|c|c|c|}
\hline \multicolumn{1}{|c|}{ Source of variation } & Type III sum of Squares & df & Mean Square & $F$ - value & $P$ - value \\
\hline Groups & 1191.383 & 4 & 297.846 & 6.580 & $.000^{*}$ \\
\hline Thermocycling & 922.477 & 1 & 922.477 & 20.378 & $.000^{*}$ \\
\hline Groups x Thermocycling interaction & 224.843 & 4 & 56.211 & 1.242 & $.309 \mathrm{~ns}$ \\
\hline
\end{tabular}

$d f:$ degrees of freedom $=(n-1), *$ Significant at $P \leq 0.05$ 
is a suitable regime for accelerated aging ${ }^{[36]}$. Gala and Darvell indicated that 10,000 cycles would be equivalent to one year of in vivo function ${ }^{[37]}$. So, 1000 thermal cycles would be equal to 1.2 months aging.

Natural products have always been a rich source of biologically active compounds. Some of these products are not used for this purpose in dentistry, but are widely used in other medical fields. The present study was conducted on natural products that have been reported in literature to have anti-MMP potential. Among them, we selected Mulberry fruits because of it contains high contents polyphenols ${ }^{[38]}$.

Various extraction conditions are reported, however there is no standard method for extraction ${ }^{[39,40]}$. The most widely used solvents for extracting phenolic compounds are water, alcohols and their water mixtures, with acid or not ${ }^{[41,42]}$. However, methanol and water were the most efficient solvents for the extraction due to the better solvation of antioxidant compounds as a result of interactions between the polar sites of the antioxidant molecules and the solvent. In addition, methanol and water, are also proton donors ${ }^{[43]}$. However, the chemical nature of phenolic compounds, method of extraction employed, storage time and conditions affect the efficiency of the extraction methods ${ }^{[44]}$. This may explain the results obtained in this study, where a significant difference between water and methanol extracts in both Morus species was detected. The mean micro TBS value of Morus nigra and Morus alba water extract is greater than its alcohol extract due to total anthocyanin pigment of water extract is higher than of its alcohol extract which is expressed as mg of cyanidin-3-O-glucoside ${ }^{[45,46]}$.

For both Morus extracts, pretreatment with water extracts were able to maintain immediate dentin bond strength. Pretreatment with Morus Nigra resulted in significant increase in micro TBS value. Several factors may have accounted for the observed results which is mainly related to the reduction of enzymatic dentin degradation.
Morus nigra and Morus alba fruits are rich in anthocyanins ${ }^{[47]}$, which are water-soluble pigments and present in our plant-based diet with little or no known toxicity ${ }^{[48]}$. Anthocyanins compounds isolated from Morus nigra and Morus alba fruits are cyanidin 3-O-rutinoside and cyanidin 3-O-glucoside which reduced extracellular matrix (ECM) proteinases including matrixmetalloproteinase-2 (MMP-2) ${ }^{[31,47]}$. Moreover, Morus nigra and Morus alba fruits rich in phenolic compounds such as catichin, epicatichin and gallic acid ${ }^{[49,50]}$, which make inhibition of matrixmetalloproteinase-2 $(\text { MMP-2 })^{[51]} \cdot$ Moreover, Catechin, epicatichin and gallic acid have been classified as a proanthocyanidin which acts as natural dentin biomodifier ${ }^{[52]}$.

The mean micro TBS of Morus nigra extracts is greater than that of Morus alba extracts due to the content of anthocyanidins compounds (cyanidin3-O-glucoside, cyanidin-3-O-rutinoside) in Morus nigrais higher than that present in Morus alba extract ${ }^{[53]}$. In addition, the total phenolic contents catichin,epicatichin and galic acid of Morus nigra fruit extract is higher than that was present in Morus alba fruits ${ }^{[54]}$. Ercisli and Orhan (2007) concluded that total phenolic and flavonoids content are affected by both plant geno type and cultivation ${ }^{[50]}$.

As mean micro TBS were affected by thermocycling, the second null hypothesis that aging of resin- dentin would not affected by the thermocycling is rejected. It was anticipated that micro TBS of all tested groups declined after thermocycling. This could be contributed to water diffusion into the adhesive interface which could be expediated especially after the teeth had already been sectioned into sticks ${ }^{[55]}$. However, Morus water extracts was able to reduce the decline in dentin bond strength after thermocycling as compared with other groups but not prevented. This could be attributed to proanthocyanidin content that functions as dentin collagen matrix stabilizer thus increasing the resistance to biodegradation ${ }^{[56,57]}$. In addition, the hydrophobicity of proanthocyanidin modified collagen films improved due to cross-linking 
between proanthocyanidin and collagen which in turn prevented moisture permeation ${ }^{[58]}$. Moreover, Vitamin C content increases the level of messenger RNA of collagen I and III and act as MMP inhibitors. This vitamin C plays an important role stabilizing the helical configuration of collagen because it is a cofactor for the amino acids hydroxyproline and hydroxylysine ${ }^{[59,60]}$.

The application of Morus water extracts was found to be beneficial to the bond strength of the etch-and-rinse adhesive and play a crucial role in bond durability. This provides the justification for further researches that are designed to investigate the effects of natural extracts on the longevity of resin-dentin bonds with longer thermocycling regimes to stimulate longer in vivo service periods of restorations.

\section{CONCLUSION}

With the limitations of this study, it may be concluded that pretreatment with Mulbery water extracts has no adverse effect on the immediate microtensile bond strength and it was able to maintain bond stability of etch and rinse adhesive to dentin.

\section{Conflict of Interest}

The authors of this manuscript certify that they have no proprietary, financial, or other personal interest of any nature or kind in any product, service, and/or company that is presented in this article.

\section{REFERENCES}

1. Mazzoni A, Tjaderhane L, Checchi V, Di Lenarde R, Salo $\mathrm{T}$, Tay F, et al. Role of dentin MMPs in caries progression and bond stability. J Dent Res. 2015;94: 241-251.

2. Frassetto A, Breschi L, Turco G, Marchesi G, Di Lenardo $\mathrm{R}$, Tay F, et al. Mechanisms of degradation of the hybrid layer in adhesive dentistry and therapeutic agents to improve bond durability- a literature review. Dent Mat. 2016; 32: 41-53.
3. Qianmin O, Hu Y, Yao S, Wang Y, Lin X. effect of matrix metalloproteinase 8 inhibitor on resin-dentin bonds. Dental Material. 2018, 756-763.

4. Tja“derhane L, Nascimento FD, Breschi L, Mazzoni A, Tersariol IL, Geraldeli S, Tezvergil-Mutluay A, Carrilho MR, Carvalho RM, Tay FR, \& Pashley DH. Optimizing dentin bond durability: control of collagen degradation by matrix metalloproteinases and cysteine cathepsins Dental Materials. 2013, 29; 116-135.

5. Mazzoni A, Scaffa P, Carrilho M, Tjäderhane L, Di Lenarda R, Polimeni A, Tezvergil-Mutluay A, Tay FR, Pashley $\mathrm{DH}, \&$ Breschi L. Effects of etch-and-rinse and self-etch adhesives on dentin MMP-2 and MMP-9 Journal of Dental Research. 2013; 92: 82-86.

6. Sanabe ME, Costa CA, Hebling J. Exposed collagen in aged resin-dentin bonds produced on sound and cariesaffected dentin in the presence of chlorhexidine. J Adhes Dent. 2011;13:117-24.

7. Pashley DH, Tay FR, Yiu C, Hashimoto M, Breschi L, Carvalho RM and Ito $\mathrm{S}$.. Collagen degradation by host-derived enzymes during aging. J Dent Res. 2004;83:216-21.

8. Vidal CM, Tjäderhane L, Scaffa PM, Tersariol IL, Pashley D, Nader HB, Nascimento F.D. and Carrilho M.R..: Abundance of MMPs and cysteine cathepsins in caries-affected dentin. J Dent Res. 2014;93:269-74.

9. Tavergil-Mutluay K, Hoshika T, Carrilho M, Breschi L, Tjaderhane L, et al. The requirement of zinc and calcium ions functional MMP activity in demineralized dentin matrices. Dent Mater. 2010; 26:1059-67.

10. Breschi L, Martin P, Mazzoni A, Nato F, Carrilho M, Tjaderhane L, Visitini E, Cadenaro M, Tay FR, De Stefano Dorigo E, \& Pashley DH. Use of a specific MMP-inhibitor (galardin) for preservation of hybrid layer Dental Materials. 2010; 26:571-578.

11. Liu Y, Tjaderhane L, Breshi L, Mazzoni A, Li N, Mao J, et al. Limitations in bonding to dentin and experimental strategies to prevent bond degradation. J Dent Res. 2011; 90:953-68.

12. Scheffel D, hebling J, Scheffel R, Agee K, Turco G, de Souza C, et al. Inactivation of matrix-bound matrix metalloproteinases by cross-linking agents in acid-etched dentin. 2014; 39: 152-185.

13. Perota C, Kamozaki M, Gutierrez N, Tay R, Pucci C. Effect of matrixmetalloprotinase inhibiting solutions and aging solutions methods on dentin bond strength. The Journal of adhesive dentistry. 2015; 17: 347-352. 
14. Zheng P, zaruba m, Attin T, Wiegand A. Effect of different matrix metalloproteinase inhibitors on microtensile bomd strength of an etch nd rinse and self etching adhesive to dentin. Operative Dentistry. 2015; 40: 80-86.

15. Carriho M, Geraldeli S, Tay F, de Goes M, Carvalho R, Tjaderhane L, et al. In vivo preservation of the hybrid layer by chlorhexidine. J Dent Res. 2007; 86: 529-33.

16. Monteiro TM, Basting RT, Turssi CP, França FM, Amaral FL.: Influence of natural and synthetic metalloproteinase inhibitors on bonding durability of an etch-and-rinse adhesive to dentin. Int J Adhes Adhes. 2013;47:83-8.

17. Lessa F, Nogueira L, Huck C, Hebling J, Costa C. Transdentinal cytotoxic effects of different concentrations of chlorohexidine gel applied on acid- conditioned dentin substrate. J Biomed Mater res B Appl Biomater. 2010; 92: 40-7.

18. Tu Y, Yang C, Chen R, Chen M. Effect of chlorohexidine on stem cells from exfoliated deciduous teeth. J Formos Med Assoc. 2015; 114: 17-22.

19. Wang 1 L and Stoner G. Anthocyanins and their role in cancer prevention. Cancer Lett. 2008; 269: 281-290.

20. Brandstetter H, Grams F, Glitz D, Lang A, Huber R, Bode W, Krell HW, Engh RA. The 1.8-A crystal structure of a matrix metalloproteinase 8-barbiturate inhibitor complex reveals a previously unobserved mechanism for collagenase substrate recognition. J Biol Chem. 2001;276:17405-17412.

21. Khoo H, Azlan A, Tang S, Lim S. Anthocyanidins and anthocyanins: colored pigments as food, pharmaceutical ingredients, and the potential health benefits. FOOD \& NUTRITION RESEARCH, 2017;61: 1-21.

22. Suttie JM. "Morus alba L". Plant Production and Protection. Food and Agricultural Organization of the United Nations. Retrieved 20 October 2012.

23. Gecer M, Akin M, Gundogdu M, Eyduran S, Ercisli S, Eyduran E. Organic acids,sugars, phenolic compounds, and some horticultural characteristics of black and white mulberry accessions from Eastern Antatolia. Can.J.Plant Sci.2015;95:27-33.

24. Huang H, Ou T, Wang C. "Mulberry (Sang Shèn Zî) and its Bioactive Compounds, the Chemoprevention Effects and Molecular Mechanisms In Vitro and In Vivo" Journal of Traditional and Complementary Medicine. 2013; 3: 7-15.

25. Zhang H, Feei Ma ZID , Luo X, Li X. Effects of Mulberry Fruit (Morus alba L.) Consumption on Health Outcomes: A Mini-Review. Antioxidants 2018, 7, 69- 82.
26. K. Mpark, J.S You, H. Ylee, N. Ibaek, J. Khwang "Kuwanon G: an antibacterial agent from the root bark of Morus alba against oral pathogens" Journal of Ethnopharmacology. 2003; 84: 181-185

27. Yang X., Yang L., Zheng H "Hypolipidemic and antioxidant effects of mulberry (Morus alba L.) fruit in hyperlipidaemia rats". 2010; 48: 2374-2379.

28. Kang, T.H.; Hur, J.Y.; Kim, H.B.; Ryu, J.H.; Kim, S.Y. Neuroprotective effects of the cyanidin-3-O-beta-D-glucopyranoside isolated from mulberry fruit against cerebral ischemia. Neurosci. Lett. 2006, 391, 122-126.

29. Ghimeray A, jung U, Lee H, Kim Y, Ryu E, Chang M. In vitro antioxidant, collagenase inhibition, and in vivo antiwrinkle effect of combined formulation containing Punica grantum, Ginkgo biloba, Ficus carica and morus alba fruits extract. Clinical Cosmotic and Investigationaln Dermatology. 2015; 8: 389-396.

30. Pawlowska AM, Oleszek W, Braca A "Quali-quantitative analyses of Flavonoids of Morus nigra L. and Morus alba L. (Moraceae) fruits". J Agric Food Chem. 2008; 14; 5: $3377-80$.

31. Hung H, Shih Y, Chang Y, Hung C, Wang C. "Chemoinhibitory Effect of Mulberry Anthocyanins on Melanoma Metastasis Involved in the Ras/PI3K Pathway" J. Agric. Food Chem. 2008, 56, 9286-9293

32. De Munck J, Mine A, Vivan Cardoso M, De Almeida Neves A, Van Landuyt K, Poitevin A, \& Van Meerbeek B. Effect of dentin location and long-term water storage on bonding effectiveness of dentin adhesives Dental Materials Journal. 2011; 30: 7-13.

33. Shirai K, De Munck J, Yoshida Y, Inoue S, Lambrechts P, Suzuki K, Shintani H, \& Van Meerbeek B. Effect of cavity configuration and aging on the bonding effectiveness of six adhesives to dentin Dental Materials . 2005; 21:110-124.

34. De Munck J, Van den Steen PE, Mine A, Van Landuyt KL, Poitevin A, Opdenakker G, \& Van Meerbeek B. Inhibition of enzymatic degradation of adhesive-dentin interfaces Journal of Dental Research.2009; 88:1101-1106.

35. Cadenaro M, Pashley DH, Marchesi G, Carrilho M, Antoniolli F, Mazzoni A, Tay FR, Di Lenarda R, \& Breschi L. Influence of chlorhexidine on the degree of conversion and E-modulus of experimental adhesive blends Dental Materials. 2009; 25:1269-1274. 
36. Sauro S, Pashley DH, Montanari M, Chersoni S, Carvalho RM, Tole- dano M, Osorio R, Tay FR, Prati C. Effect of simulated pulpal pressure on dentin permeability and adhesion of self-etch adhesives. Dent Mater 2007;23:705713.

37. Gale MS and Darvell BW. Thermal cycling procedures for laboratory testing of dental restorations. J Dent 1999;27:89-99.

38. Ionica M, Nour V, Trandafir I. Bioactive compound and antioxidant capacity of some Morus species . South Western Journal of Horticulture, Biology and Environment. 2017;8: 79-88.

39. Cacace JE, Mazza G: Optimization of extraction of anthocyanins from black currants with aqueous ethanol. J Food Sci 2003, 72:240-248.

40. Bucić-Kojić A, Planinić M, Tomas S, Bilić M, Velic D: Study of solid-liquid extraction kinetics of total polyphenols from grape seeds. J Food Eng 2007, 81:236-242.

41. Naczk M, Shahidi F: Phenolics in cereals, fruits and vegetables: occurrence, extraction and analysis. J Pharm Biomed Anal 2006, 41:1523-1542.

42. Michiels JA, Kevers C, Pincemail J, Defraigne JO, Dommes J: Extraction conditions can greatly influence antioxidant capacity assays in plant food matrices. Food Chem 2012, 130:986-993.

43. Boein J, Barizão E, Silva B, Montanher P, Almeida V, Visentainer J. Evaluation of solvent effect on the extraction of phenolic compounds and antioxidant capacities from the berries: application of principal component analysis. Chemistry Central Journal 2014, 8:48-57.

44. Naczk M, Shahidi F: Extraction and analysis of phenolics in food. J Chromatogr A 2004, 1054:95-111.

45. Dimirijavic D, Kostic D, Dtojanovi G, Mitic S, Mitic M, Micic R. "Polyphenol contents and antioxidant activity of five fresh fruit Morus spp. (Moraceae) extracts" Agro FOOD Industry Hi Tech - vol 24(5) - September/October 2013

46. Yang HJ, Kim MJ, Kang ES, Kim DS, Park S “Red mulberry fruit aqueous extract and silk proteins accelerate acute ethanol metabolism and promote the anti-oxidant enzyme systems in rats."Mol Med Rep. 2018 Jul;18(1):1197-1205

47. Pei-NiChen P, Shu-ChenChu, Hui-LingChiou, Wu-HsienKuo, Chui-Liang Chiang, Yih-Shou Hsieh "Mulberry anthocyanins, cyanidin 3-rutinoside and cyanidin 3-gluco- side, exhibited an inhibitory effect on the migration and invasion of a human lung cancer cell line "Cancer Letters" . 2006;235: 248-259.

48. Nabae, K.; Hayashi, S.M.; Kawabe, M.; Ichihara, T.; Hagiwara, A.; Tamano, S.; Tsushima, Y.; Uchida, K.; Koda, T.; Nakamura, M.; et al. A 90-day oral toxicity study of purple corn color, a natural food colorant, in F344 rats. Food Chem. Toxicol. 2008, 46, 774-780. Int. J. Mol. Sci. 2012, 136301

49. Muhammad Arfan, Rasool Khan, Anna Rybarczyk and Ryszard Amarowicz. "Antioxidant Activity of Mulberry Fruit Extracts” Int. J. Mol. Sci. 2012;13: 2472-2480.

50. Ercisli S and Orhan E. Chemical composition of white (Morus alba), red (Morus rubra) and black (Morus nigra) mulberry fruits. Food Chem. 2007, 103, 1380-1384.

51. Demeule M, Brossard M, Pagé M, Gingras D, Béliveau R. Matrix metalloproteinase inhibition by green tea catechins. Biochim Biophys Acta. 2000;1478:51-60.

52. Nagpal R, Singh P, Singh SP. Proanthocyanidin: A natural dentin biomodifier in adhesive dentistry. I Res Dent. 2016; $4: 1-6$

53. Yuting Li, Tao Bao, Wei Chen. "Comparison of the protective effect of black and white mulberry against ethyl carbamate-induced cytotoxicity and oxidative damage" J Agric Food Chem. 2018.14;56:3377-80.

54. Sofia P, Ariana-Bianca V, Corina C, Gogoasa I, Corina G, Cerasela P. Chemical characterisation of white (Morus alba), and black (Morus nigra) mulberry fruits. Journal of Horticulture, Forestry and Biotechnology. 2014; 18:133- 135 .

55. Feitosa VP, Leme AA, Sauro S, Correr-Sobrinho L, Watson TF, Sinhoreti MA, \& Correr AB. Hydrolytic degradation of the resin-dentine interface induced by the simulated pulpal pressure, direct and indirect water ageing Journal of Dentistry.2012; 40: 1134-1143.

56. Verma R, Singh UP, Tyagi SP, Nagpal R, Manuja N. Longterm bonding effectiveness of simplified etch-and-rinse adhesive to dentin after different surface pre-treatments. J Conserv Dent 2013;16:367-70.

57. Nagpal R, Manuja N, Pandit IK. Effect of proanthocyanidin treatment on the bonding effectiveness of adhesive restorations in pulp chamber. J Clin Pediatr Dent 2013; 38:49-53 
58. Castellan CS, Pereira PN, Grande RH, Bedran-Russo AK. Mechanical characterization of proanthocyanidin-dentin matrix interaction. Dent Mater 2010;26:968-73.

59. Nusgens BV, Humbert P, Rougier A, Colige AC, Haftek M, Lambert CA, et al. Topically applied vitamin $\mathrm{C}$ enhances the mRNA level of collagens I and III, their processing en- zymes and tissue inhibitor of matrix metalloproteinase 1 in the human dermis. J Invest Dermatol. 2001;116(6):853-9.

60. Fonseca B, Pleffken P, Balducci I, Pucci C, Tay F, Amelia M, de Araujo M. New trends in dentin bonding: treatment with Chlorhexidine, Hyaluronic acid, vitamin $\mathrm{C}$ and green tea. Braz Dent Sci .2013;16:56-62. 